\title{
Ergonomics Concerns (OHS) to Improve Productivity in Brick Industry
}

\author{
Dubey AD*, Manish Verma and Ashish kr Khandelwal
}

Choukse Engineering College, Bilaspur, Chhattisgarh, India

\begin{abstract}
A typical trait of our civilization is, since primitive time human being always try to reduce work load with the help of machines or manual devices. It is observed that machines can also not continue its working for very long without human intervention, if continue there might be chance of failure without maintenance. Work is done by man-machine system. Productivity is directly associated with 5 M's namely man, machine, material, money and management . In this project emphasis has been given to improve the productivity in small scale industries i.e. brick industries . Ergonomics has taken as subsystem under which fatigue and safety is analyzed. Wrong postures gives different kind of problems muscular, ophthalmological and orthopedic cause reduction in productivity. With the provision of correct body posture and using different productivity models application of ergonomics reduces the absentia of workers and productivity can be improved in small scale industries. In this way we can improve the GDP of our country by providing attention towards ergonomics (OHS).
\end{abstract}

Keywords: OHS; GDP; DC; MMH; Po-P; MSD; KPA

\section{Introduction}

Ergonomics word is derived from two Greek words ergos means work nomos means law. This word was introduced in 1949 by a group of British scientists who were concerned with the efficient use of complex military equipment during the Second World War. We can say it is human engineering this word is used in country like USA but in European countries this is called Ergonomics. Ergonomics is multidisciplinary area of study. Various disciplines have influence on human factors.

1. Engineering: Design and work system suitable for workers.

2. Physiology: Study of man and its working environment

3. Anatomy: Study of body dimensions and relations for work design.

4. Psychology: Study of adaptive behavior and skills of people.

5. Industrial Hygiene: occupational hazards and workers health.

These are following areas where we can study about human engineering or ergonomics:

i. Anthropometry and bio mechanics.

ii. Control of physical work environment.

iii. Design of man -machine system.

iv. Accidents fatigue and safety

v. Work place design.

Occupational health and safety (OHS) primarily intends to maintain the working ability of the labor force as well as to identify, assess and prevent hazards within the working environment. Ergonomics, on the other hand, combines all of these issues to improve workers' efficiency and well being and maintain industrial production through the design of an improved workplace. OHS and ergonomic applications therefore work together to satisfy the needs of changing local people's attitudes, local work methods and/or traditional ways of doing things. These issues are important for many developing countries (DCs), because the effects of poor health and lack of safety facilities, and non ergonomics conditions exist in various workplaces are a hindrance to the national economy and social progress. Since implementing the full concept of OHS and ergonomics application is a priority, understanding the meaning of the terms related to OHS and ergonomics applications is a major source of workplace improvement. It is therefore important for both foreign and local investors to investigate workplaces, to know how a tool, machinery and production process would match the local workers' physical and mental capabilities of the local population. OHS and ergonomics issues have a connection with various components in the regional economy since the provision of health, hygiene and safety in the workplace contributes to economic growth processes in a number of ways. OHS and ergonomic issues are also related with the production economy and social progress, and thus, important components of gross domestic product (GDP) - which are considered as inputs into the national economy through industrial development. It is therefore important to know what socio-economic and industrial strategies would be most fruitful if OHS and ergonomic applications are to be implemented in practice. This is because the GDP lost in work-related injuries and occupational disease stemming from a poor work environment is not counted in DCs. In many DCs, physical work practiced as manual materials handling $(\mathrm{MMH})$ and strenuous tasks which usually take a toll as injuries, accidents and production loss, because numerous risky and hazardous jobs and strenuous tasks still have yet to be semi-automated or be transferred to other forms of controlled environment. Hundreds of thousands of workers living in DCs will be at risk if no future attempts are made successful for the improvement of health and hygiene. For unhygienic workplaces, these risks are real, and there is a long term trends in occupational exposure in DCs. The rapid rate of changes in working life today also requires several types of flexibility with the consideration of occupational health, industrial hygiene and safety requirements in various workplaces [1-3].

New industrial entrepreneurs also need to have the capacity to

*Corresponding author: Dubey AD, Choukse Engineering College, Bilaspur, Chhattisgarh, India, Tel: +91-7752-302100; E-mail: addubey@sify.com

Received May 04, 2014; Accepted February 05, 2015; Published February 15 , 2015

Citation: Dubey AD, Verma M, Khandelwal AK (2015) Ergonomics Concerns (OHS) to Improve Productivity in Brick Industry. J Appl Mech Eng 4: 156 doi:10.4172/2168-9873.1000156

Copyright: $\odot 2015$ Dubey AD, et al. This is an open-access article distributed under the terms of the Creative Commons Attribution License, which permits unrestricted use, distribution, and reproduction in any medium, provided the original author and source are credited. 
Citation: Dubey AD, Verma M, Khandelwal AK (2015) Ergonomics Concerns (OHS) to Improve Productivity in Brick Industry. J Appl Mech Eng 4: 156. doi:10.4172/2168-9873.1000156

Page 2 of 5

provide a rational basis of new thinking and solutions for sustainable development of workplace safety and health. The efficiency of the work force should increase as the workers could devote their attention to the jobs rather than to the tools needed to pursue their job tasks. This devotion can be introduced as formal and informal methods to assist individuals in acquiring knowledge on OHS, as well as an ergonomic way of doing things. It is also believed that the sustainable development of the workplace will be achieved for long term benefits if health, safety and ergonomic issues are given priority in the local context (Figure 1).

\section{Literature Review}

Managers usually associate ergonomics with occupational health and safety and related legislation, not with business performance. In many companies, these decision makers seem not to be positively motivated to apply ergonomics for reasons of improving health and safety. In order to strengthen the position of ergonomics and ergonomists in the business and management world, we discuss company strategies and business goals to which ergonomics could contribute. Conceptual models are presented and examples are given to illustrate: (1) the present situation in which ergonomics is not part of regular planning and control cycles in organizations to ensure business performance; and (2) the desired situation in which ergonomics is an integrated part of strategy formulation and implementation. In order to realize the desired situation, considerable changes must take place within the ergonomics research, education and practice community by moving from a health ergonomics paradigm to a business ergonomics paradigm, without losing the health and safety goals. It shows that ergonomics do not get proper attention for implementation in large as well as small scale industries, but it is observed that OHS and ergonomics implementation is must for all kind of industries for employees health and safety and ultimately we say if workers satisfied and healthy means it increases productivity [4].

Employee participation and commitment from top management are important factors in effective occupational health and safety (OHS) management. However, between top management and employees there are middle managers, who are given little room in the top management/ employee dichotomy. In this context, using the shipping industry as a case study, this paper investigates the impact of senior officer leadership on ratings' participation in OHS management. Results suggest that while ratings' precarious employment coupled with a steep hierarchy of command on board ships make upward communication in formal environments practically impossible, it is possible for senior officers to elicit effective participation from ratings by making good use of informal settings, working alongside ratings and engaging with them in social activities. Such leadership efforts bring in temporary relief to the constraints of participation and create spaces for them to contribute in the management of shipboard OHS. In this kind of industries OHS and ergonomics implementation must should be separately handled by department OHS and ergonomics $[5,6]$.

\section{Problem Identification}

1. A Study of brick industry revealed that the productivity of the industry decreased as compared to the last three year.

2. It was found that the working condition and workers are the same.

3. Absentia is increased and interest in work has been reduced since last third year. Increased complain of body related problems.

4. Workers are switching over in another profession.
5. Owners are not implementing OHS norms in industry [7-9].

\section{Methodology}

Productivity measurement by PO-P approach consists of the following steps:

1) Identifications of sub systems

2) Identification of KPA's in each of the sub systems

3) Setting of performance objectives

4) Ranking and weighting of sub systems, KPA's and Performance Objectives

5) Determination of Objectivated Output

6) Calculation of Productivity Index

\section{PO-P: The model}

Under PO-P approach productivity index for the system is built up in stages, from the productivity indices of the sub - systems constituting the system. Productivity index of a sub-system is, in turn, built up from the productivity indices of the Key Performance Area (KPA's) of that sub-system (Figure 2).

Let,

$\mathrm{u}=$ the sub-system

$\mathrm{v}=$ the $\mathrm{KPA}$

$\mathrm{y}=$ the performance objective $(\mathrm{PO})$

$\mathrm{w}=$ the weightage factor

$\mathrm{O}_{\mathrm{yvu}}=$ the performance value of PO-y in KPA-v in sub-system $\mathrm{u}$

$\mathrm{O}_{\text {yvu }}{ }^{*}=$ the objectivated output of PO-y in KPA-v in sub-system u

Productivity Index PI of a system S, is arrived at as,

$P I=\sum_{u=1} W_{u}(P I)_{u}$

Where,

$\sum_{u=1} W_{u}=1$

$(\mathrm{PI})_{\mathrm{u}^{\prime}}$, the Productivity Index of sub system $\mathrm{u}$ is determined as,

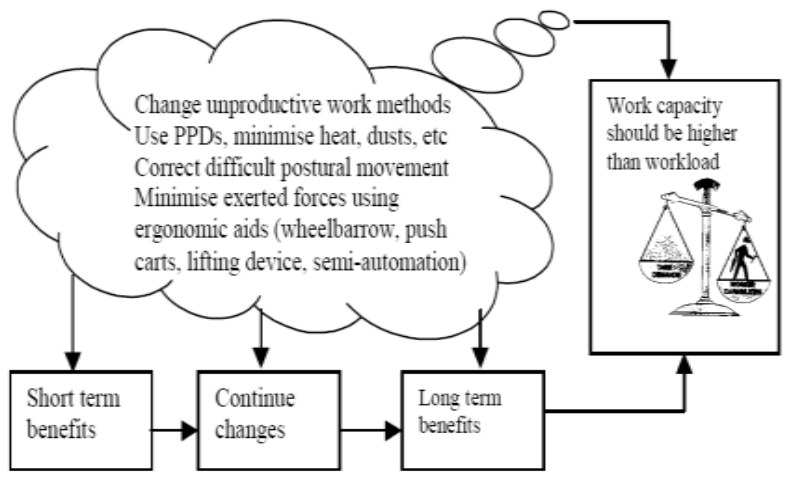

Figure 1: A conceptual model based on health, safety and ergonomic measures for sustainable workplace improvement that increase working capacity and decrease workload. 


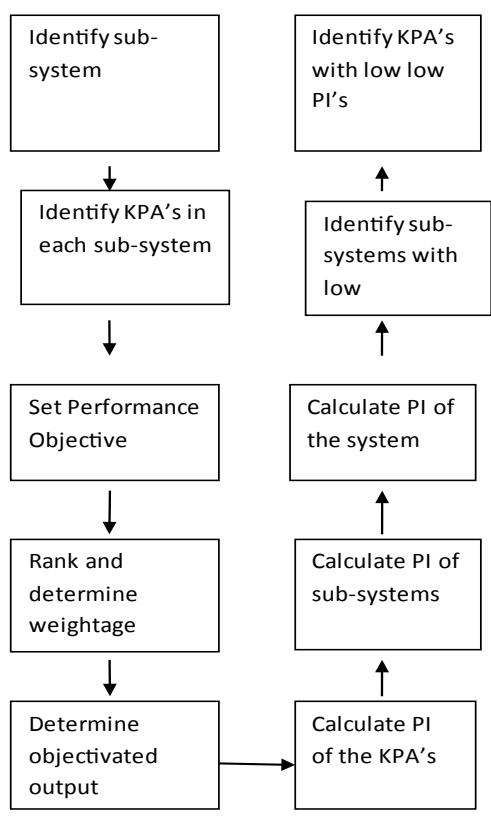

Figure 2: Flow chart for the procedure for use of PO-P approach for productivity measurement

$$
(P I)_{\mathrm{u}}=\sum_{V=1} W_{v u}(P I)_{v u}
$$

Where, $\sum_{V=1} W_{v u}=1$ for all u'

(PI) ${ }_{\text {vu, }}$ Productivity Index of Key Performance Area, v of subsystem $\mathrm{u}$ is given as,

$$
(P I)_{v u}=\sum_{y=1} W_{y v u} \frac{O y v u}{O^{*} y v u}
$$

Where,

$$
\sum_{y=1} W_{y v u}=1, \text { for all } \mathrm{u} \text { and } \mathrm{v}
$$

Substituting values of (PI) ${ }_{\text {vu }}$ from equation 3 in equation 2, Productivity Index $(\mathrm{PI})_{\mathrm{u}}$ of a sub-system $\mathrm{u}$, can be rewritten as,

$$
(\mathrm{PI})_{\mathrm{u}}=\sum_{y=1} \sum_{v=1} W_{v u} W_{y v u} \frac{O y v u}{O * y v u}
$$

Value of (PI) from equation 4 can be substituted in equation 1 to provide PI, the Productivity Index of a system S, as

$$
\mathrm{PI}=\sum_{y=1} \sum_{v=1} \sum_{y=1} W_{u} W_{v u} W_{y v u} \frac{O y v u}{O * y v u}
$$

A typical industrial organization engaged in manufacturing and marketing of engineering goods can be considered to operate as a system with the following sub-systems;

- Production sub-system

- Marketing sub-system

- Financial sub-system

- Technology sub-system

- HRD sub-system
- Materials sub-system.

\section{Different Types of Hazards}
A. Musculoskeletal disorders (MSD’S.)
B. Air.
C. Thermal exposure.

\section{Diseases and Disorders}

\section{Leukemia}

The cause of most human leukemia is unknown. It is a kind of cancer in which abnormal white blood cells multiply in an uncontrolled manner. They interfere with the production of normal white blood cells. Leukemia affects the production of red blood cells.

\section{Bursitis}

Bursitis is a disorder that causes pain in the body's joints. It most commonly affects the shoulder and hip joints. It is caused by an inflammation of the bursa, small fluid-filled bags that act as lubricating surfaces for muscles to move over bones. This inflammation usually results from over activity of an arm or leg.

\section{Osteoporosis}

Osteoporosis is a disease resulting in the loss of bone tissue. In osteoporosis, the cancellous bone loses calcium, becomes thinner, and may disappear altogether.

\section{Sprains}

A sprain is an injury to a ligament or to the tissue that covers a joint. Most sprains result from a sudden wrench that stretches or tears the tissues of the ligaments. A sprain is usually extremely painful. The injured part often swells and turns black and blue.

\section{Fractures}

A fracture is a broken bone.

\section{Scurvy}

Scurvy is a disease caused by lack of ascorbic acid (vitamin C) in the diet. If a person does not get enough vitamin $\mathrm{C}$, any wound he or she might have heals poorly. The person also bruises easily. The mouth and gums become sore. The gums bleed, and the teeth may become loose. Patients lose their appetite, their joints become sore, and they become restless.

\section{Tendinitis}

Tendinitis is a disorder involving stiffness or pain in the muscles or joints. It is often called rheumatism.

\section{Arthritis}

There are more than 100 diseases of the joints referred to as arthritis. Victims of arthritis suffer pain, stiffness, and swelling in their joints. Osteoarthritis, also called degenerative joint disease, occurs when a joint wears out. Many elderly people have osteoarthritis, and the disease may also occur if a joint has been injured many times. The joints most frequently affected are those of the hands, hips, knees, lower back, and neck.

\section{Scoliosis}

Scoliosis is a side-to-side curve of the spine. This condition becomes 
apparent during adolescence. It is unknown why Scoliosis affects more girls than boys.

\section{Talipes equinovarus}

Talipes equinovarus, often called clubfoot is an abnormal condition of the foot, usually present at birth. The foot is bent downward and inward so that the person can walk only on the toes and on the outside of the foot. Sometimes the foot is bent upward and outward so that the person can use only the heel for walking.

\section{Kyphosis}

Kyphosis, also called hunchback is a forward bending of the spine. Kyphosis is caused by any condition that deforms the bones of the upper part of the spine so that the person is bent forward. Diseases that cause kyphosis include tuberculosis, syphilis, and rheumatoid arthritis.

\section{Poliomyelitis}

Poliomyelitis, also called polio, is a serious infection caused by a virus. A polio virus may attack the nerve cells of the brain and spinal cord, causing paralysis. Some patients show only mild symptoms, such as fever, headache, sore throat, and vomiting. Symptoms may disappear after about a day.

\section{Female desease}

The female workers engaged into clay brick production in subtropic climate are exposed to dust and heating microclimate. Scientific and technologic progress has a great positive influence on the improvement of work conditions in the stated production. Respiratory diseases turned out to take the first place in the structure of morbidity with transitory disablement. The clinical studies established the correlation between the work conditions and gynecologic morbidity, occurrence of complicated pregnancy and delivery, impaired physical development and health status of newborns and children.

\section{Pneumoconiosis}

The term 'pneumoconiosis' refers to a group of lung diseases caused by the inhalation and retention of dust in the lung. This causes a range of granulomatous and fibrotic changes. In modern times, the most commonly occurring variant, apart from asbestosis, is coal workers' pneumoconiosis arising from the inhalation of coal dust. There is generally a long time lag between exposure and onset of the disease - 10 years in the case of coal dust and 15-60 years with asbestos - hence, most new cases or deaths from pneumoconiosis reflect the working conditions of the past (Table 1).

\section{Suggestions}

- Kiln design to improve fuel efficiency. "The big problem is no uniformity of temperature.

- The workers should work on shift basis.
- Building several kilns near each other and transferring the heat that is lost during the firing of one kiln to the next one.

- Need to develop a sun-drying process, so it eliminates the kiln.

- "We cannot do anything about the climate, but we can do a lot about the environment."

- Brick Control Act.

- Mandatory to install a minimum 50-feet height chimney with filter in every kiln for emission of smokes.

- The owners are prohibited from using all kinds of fire wood in kilns.

- Allow infertile and fallow land for setting up of brick fields, but almost in all districts many brick-fields have been set up on arable lands.

\section{Result and Discussion}

From a survey of the kilns operating in various parts of the chhattisgarh state. I have a firm conviction that it is very much possible to make these kilns 'CLEAN' to provide congenial and hygienic atmosphere to the workers. The way is there, will is needed. All the improvements hinted above need be followed strictly. It will not only result in overall saving of fuel but will also make the workplace clean. Minor investments in these efforts will be more than compensated by the healthy and hygienic environment that has so far eluded the brick kilns.

It is time brick industry quits its old fashioned look of an introvert organized system and comes forward as a progressive and modern looking organization. The industry should voluntarily cooperate with statutory bodies in state and national interest to safeguard the nature and environment in its primitive form to be available to the posperity. I hope the state government will rise to be occasion and take up the challenge of providing a 'CLEAN' environment to the workers in their kilns. I am convinced they will succeed in this earnest effort.

The anticipated productivity index have increased from .6791 to .7832 . Productivity can be increased by the application OHS and Ergonomics in small scale industries by more than $10 \%$. Application of OHS and Ergonomics are generally ignored by small scale industries management people.

\section{Suggestions}

- Kiln design to improve fuel efficiency. "The big problem is no uniformity of temperature.

- The workers should work on shift basis.

- Building several kilns near each other and transferring the heat that is lost during the firing of one kiln to the next one.

- Need to develop a sun-drying process, so it eliminates the kiln.

\begin{tabular}{|c|c|c|c|c|c|c|}
\hline Code & Sub-system & Relative marks & Weightage & Sub-system & Relative marks & Weightage \\
\hline A & Production & 5 & 0.192 & Production & 5 & 0.202 \\
\hline$B$ & Technology & 5 & 0.192 & Technology & 5 & 0.208 \\
\hline $\mathrm{C}$ & Materials & 1 & 0.038 & & & \\
\hline $\mathrm{D}$ & Goal \& Values & 1 & 0.038 & & & \\
\hline$E$ & Marketing & 10 & 0.384 & Marketing & 10 & 0.417 \\
\hline \multirow[t]{2}{*}{$\mathrm{F}$} & Ergonomics & 4 & 0.153 & Ergonomics & 4 & 0.167 \\
\hline & Total & 26 & 1 & & 24 & 1 \\
\hline
\end{tabular}

Table 1: Weightage of Sub-Systems 
a) "We cannot do anything about the climate, but we can do a lot about the environment."

b) Brick Control Act.

c) Mandatory to install a minimum 50 -feet height chimney with filter in every kiln for emission of smokes.

d) The owners are prohibited from using all kinds of fire wood in kilns.

\section{Conclusion}

The existing level of productivity is measured using technique of productivity measurement, termed as Performance Objectives - productivity (PO-P). PO-P approach lays stress on the aspects of identification of areas with low productivity so as to bring about improvements. Its basic philosophy lies in the belief that input resources of an organization cannot be viewed in isolation. A methodology has been presented to help in identification of key performance areas, performance objectives and their weightage. To include performance objectives of qualitative nature's questionnaire is used. For productivity measurement three sub - systems mainly 'Technology', 'Workplace' and 'Market' has been identified where improvement in productivity was needed. For productivity enhancements, in the area of 'Technology', 'workplace' and 'Market factor', the Study looked at each of these sub - system and came up with suggestions that enhances productivity of these significantly. From a survey of the kilns operating in various parts of the Chhattisgarh state. I have a firm conviction that it is very much possible to make these kilns 'CLEAN' to provide congenial and hygienic atmosphere to the workers. The way is there, will is needed. All the improvements hinted above need be followed strictly. It will not only result in overall saving of fuel but will also make the workplace clean. Minor investments in these efforts will be more than compensated by the healthy and hygienic environment that has so far eluded the brick kilns.

\section{References}

1. Shah HS (in press) Work study and ergonomics, Dhanpat Rai \& company.

2. Banga TR, Sharma SC (2014) Industrial Organisation and Engineering Economics, Khanna Publishers.

3. Telsang $\mathrm{M}$. Industrial engineering and Production management, $\mathrm{S}$ chand \& company Itd.

4. Neumann WP (2009) Ergonomics contributions to company strategies, Canada Applied Ergonomics 40: 745-752.

5. Ergonomics and occupational safety and health.

6. Niu S (2010) Programme on Safety and Health at Work and the Environment, International Labour Organization, 4 route des Morillons, 1211 Geneva 22 Switzerland

7. Tang L, Bhattacharya S (2014) Middle managers' role in safeguarding OHS: The case of the shipping industry.

8. International Shipping and Logistics, School of Management, Plymouth University, United Kingdom.

9. Seafarers International Research Centre, School of Social Sciences, Cardiff University, United Kingdom. 